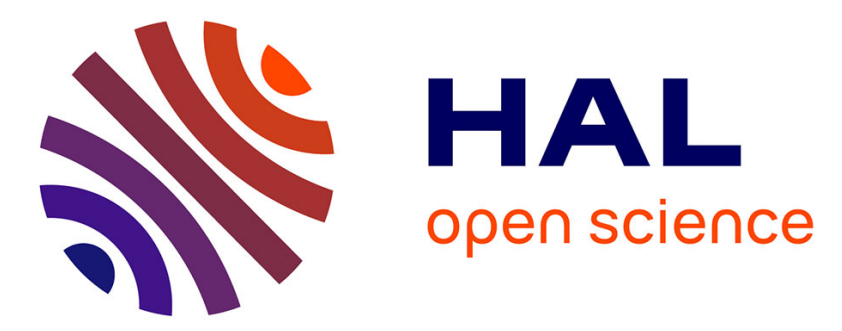

\title{
Honey bee diet in intensive farmland habitats reveals an unexpectedly high flower richness and a major role of weeds
}

Fabrice Requier, Jean Francois Odoux, Thierry Tamic, Nathalie Moreau, Mickaël Henry, Axel Decourtye, Vincent Bretagnolle

\section{To cite this version:}

Fabrice Requier, Jean Francois Odoux, Thierry Tamic, Nathalie Moreau, Mickaël Henry, et al.. Honey bee diet in intensive farmland habitats reveals an unexpectedly high flower richness and a major role of weeds. Ecological Applications, 2015, 25 (4), pp.881-890. 10.1890/14-1011.1 . hal-01162217v2

\section{HAL Id: hal-01162217 \\ https://hal.science/hal-01162217v2}

Submitted on 29 Jul 2015

HAL is a multi-disciplinary open access archive for the deposit and dissemination of scientific research documents, whether they are published or not. The documents may come from teaching and research institutions in France or abroad, or from public or private research centers.
L'archive ouverte pluridisciplinaire HAL, est destinée au dépôt et à la diffusion de documents scientifiques de niveau recherche, publiés ou non, émanant des établissements d'enseignement et de recherche français ou étrangers, des laboratoires publics ou privés. 


\title{
Honey bee diet in intensive farmland habitats reveals an unexpectedly high flower richness and a major role of weeds
}

\author{
Fabrice Requier, ${ }^{1,2,9}$ Jean-François Odoux, ${ }^{1}$ Thierry Tamic, ${ }^{1}$ Nathalie Moreau, ${ }^{3}$ Mickaël Henry, ${ }^{4,5}$ \\ Axel Decourtye, ${ }^{5,6,7}$ and Vincent Bretagnolle ${ }^{2,8}$ \\ ${ }^{1}$ INRA, UE 1255 Entomologie, Le Magneraud, BP52, 17700 Surgères, France \\ ${ }^{2}$ Centre d'Etudes Biologiques de Chizé, CNRS and Université de La Rochelle, UMR 7372, 79360 Beauvoir sur Niort, France \\ ${ }^{3}$ INRA, UE 1206 EASM, Le Magneraud, BP52, 17700 Surgères, France \\ ${ }^{4}$ INRA, UR 406 Abeilles et Environnement, Site Agroparc, 84914 Avignon, France \\ ${ }^{5}$ UMT PrADE, Site Agroparc, 84914 Avignon, France \\ ${ }^{6}$ Association de Coordination Technique Agricole ACTA, Site Agroparc, 84914 Avignon, France \\ ${ }^{7}$ ITSAP-Institut de l'abeille, 84914 Avignon, France \\ ${ }^{8}$ LTER Zone Atelier Plaine \& Val de Sèvre, Centre d'Etudes Biologiques de Chizé, CNRS, F-79360 Villiers-en-Bois, France
}

\begin{abstract}
In intensive farmland habitats, pollination of wild flowers and crops may be threatened by the widespread decline of pollinators. The honey bee decline, in particular, appears to result from the combination of multiple stresses, including diseases, pathogens, and pesticides. The reduction of semi-natural habitats is also suspected to entail floral resource scarcity for bees. Yet, the seasonal dynamics and composition of the honey bee diet remains poorly documented to date. In this study, we studied the seasonal contribution of massflowering crops (rapeseed and sunflower) vs. other floral resources, as well as the influence of nutritional quality and landscape composition on pollen diet composition over five consecutive years. From April to October, the mass of pollen and nectar collected by honey bees followed a bimodal seasonal trend, marked by a two-month period of low food supply between the two oilseed crop mass-flowerings (ending in May for rapeseed and July for sunflower). Bees collected nectar mainly from crops while pollen came from a wide diversity of herbaceous and woody plant species in semi-natural habitats or from weeds in crops. Weed species constituted the bulk of the honey bee diet between the mass flowering crop periods (up to $40 \%$ ) and are therefore suspected to play a critical role at this time period. The pollen diet composition was related to the nutritional value of the collected pollen and by the local landscape composition. Our study highlights (1) a food supply depletion period of both pollen and nectar resources during late spring, contemporaneously with the demographic peak of honey bee populations, (2) a high botanical richness of pollen diet, mostly proceeding from trees and weeds, and (3) a pollen diet composition influenced by the local landscape composition. Our results therefore support the Agri-Environmental Schemes intended to promote honey bees and beekeeping sustainability through the enhancement of flower availability in agricultural landscapes.
\end{abstract}

Key words: Agri-Environmental Schemes; agricultural landscape; Apis mellifera L.; floral resources; honey reserves; long-term monitoring; palynological identification; pollen collections; pollen quality.

\section{INTRODUCTION}

Over the past 50 years, agricultural landscapes have been profoundly modified to meet growing food requirements (Godfray et al. 2010). Intensification of agricultural systems has resulted in a loss of habitats and associated biodiversity (Tilman et al. 2001). Bees, in particular, have substantially declined in agricultural landscapes in Europe and North America (Winfree et al. 2009). Bees are critical for pollination of crops and wild plants (Klein et al. 2007, Rader et al. 2009), and the honey bee (Apis mellifera L.) is regarded as the most

Manuscript received 28 May 2014; revised 22 October 2014; accepted 14 November 2014. Corresponding Editor: A. K. Brody.

${ }^{9}$ E-mail: requierf@gmail.com important pollinator in farmlands due to its high numbers in a single nest (Rader et al. 2009). However, both wild bees and honey bees are declining. Their decline appears best explained by multiple stressors, encompassing loss of genetic diversity and vitality, pests and pathogens, and exposure to pesticides (Potts et al. 2010, Vanbergen et al. 2013).

In addition, a lack of alternative food resources to crops may affect honey bee foraging (Naug 2009) and colony health. However, our current knowledge about honey bee diet in intensive cereal systems is poor. Larvae, adult workers, and queens rely exclusively on nectar and pollen for food (Haydak 1970). Nectar is the main source of energy for adult workers and may be stored in the form of honey. Pollen is consumed by both adults and larvae (Keller et al. 2005), and is their only 
source of protein and lipids (Haydak 1970). Despite the widely recognized importance of these floral resources, to the best of our knowledge, no study has ever considered both pollen and nectar diet for bees in farmland landscapes.

Here, we assessed the importance of pollen and nectar to honey bees in intensive farmland habitats, using empirical data collected at a large spatial scale over five consecutive years. Food resources brought back to hives were surveyed throughout the beekeeping season (March to October), and in various farmland landscape types. The study agrosystem includes two oilseed crops, rapeseed (Brassica napus) and sunflower (Helianthus annuus). Oilseed crops are mass-flowering and highly rewarding for honey bees, providing abundant resources (Rollin et al. 2013). However, mass-flowering occurs over a restricted period of time (about 20-30 days) separated by temporal gaps, e.g., of two months between rapeseed and sunflower blooms, occurring in April and July, respectively. During gap periods, bees may rely on wild floral resources within scarce semi-natural habitats. Our overarching objective was to describe the seasonal variations in honey bee diet, especially with regard to the relative contribution of crops vs. other plant species. First, we tested the prediction that the amount of collected pollen and nectar follows a bimodal seasonal pattern, driven by the two main oilseed crops, with a heavier reliance on wild plants in between. Second, to assess the relative contribution of mass-flowering crops and other floral resources to the honey bee diet, we determined the botanical origins of bee-collected pollen and nectar. Third, we investigated the links between the nutritional value of pollen and its occurrence in honey bee diet. Finally, we assessed the extent to which diet dissimilarity among apiaries varies with distance, as an indirect measure of local landscape effects on dietary composition.

\section{Material and Methods}

\section{Study area and experimental design}

The study was carried out in the Long-Term Ecological Research (LTER) Zone Atelier Plaine et Val de Sèvre in central western France $\left(46^{\circ} 23^{\prime} \mathrm{N}, 0^{\circ} 41^{\prime} \mathrm{W}\right.$; Appendix A) during five consecutive beekeeping seasons (2008-2012). The local agricultural landscape is composed of a high proportion of arable land ( $>75 \%$ of total land cover), of which a large part is dedicated to cereal production $(45 \%$ of total land cover) as well as sunflower (10\%), rapeseed (9\%), and maize (Zea mays, $8 \%$ ) production (see Plate 1). The study area $\left(450 \mathrm{~km}^{2}\right)$ was divided into $5010-\mathrm{km}^{2}$ plots that were $3.3 \mathrm{~km}$ on each side (Odoux et al. 2014; Appendix A). Every year, 10 of these plots were randomly chosen (with no replacement among years) and a five-hive apiary was set up as close as possible to each plot center. On average, apiaries had access to 50.1 \pm 30.3 ha (mean $\pm \mathrm{SD}$ ) of rapeseed and $73.5 \pm 36.0$ ha of sunflower within a $1.5 \mathrm{~km}$ radial distance. All honey bee colonies originated from a livestock managed by a local professional apicultural association (Association de développement apicole Poitou-Charentes, ADA PC), from an $A$. mellifera mellifera $\times$ caucasica strain. Colonies were managed according to local beekeeping professional practices, and underwent a bimonthly survey which included a population size and state of health assessment and a pollen and nectar sampling routine (Plate 1; see also Odoux et al. 2014).

\section{Seasonal pattern of pollen and nectar collected mass}

The seasonal pollen and nectar collection dynamics were determined by 780 and 1460 mass data points, respectively. Pollen samples were obtained by fitting pollen traps at each hive entrance for $24 \mathrm{~h}$ every $8-12$ days from late March to October, except for weak or orphan colonies (Odoux et al. 2014). Pollen traps retain about $10 \% \pm 5 \%$ of all the collected pollen brought back to the hive (Lavie and Fresnaye 1963). Assuming the percent retained is stable, the weight of the collected pollen loads may be viewed as a proxy of daily collected pollen mass per colony. Pollen trap contents were pooled among the five hives of apiaries within each sampling date, freed from exogenous impurities, ovendried for $48 \mathrm{~h}$ at $45^{\circ} \mathrm{C}$, and weighed to the nearest $0.01 \mathrm{~g}$ (Sartorius balance).

In contrast to pollen sampling, nectar sampling requires hives to be opened. To reduce disturbance effects of opening hives, we carried out nectar mass measurements at a slightly lower frequency (every $14 \pm$ 2 days, from late March to October) and for only three out of five hives (always the same ones) per apiary (Odoux et al. 2014). For each hive, all frames were weighed without honey bees, the brood area was measured, converted to nectar mass, and finally subtracted from the total frame mass (see methodological details in Odoux et al. 2014). This method assesses the total mass of food reserves available to bees in the brood chamber, therefore cumulating nectar and honey. In the following, we call this quantity "nectar," though it comprises both nectar and honey.

\section{Contribution of flowering crops vs. other floral resources to honey bee diet}

The relative contribution of mass-flowering crops to total pollen and nectar diet was assessed based on the identification of pollen grains found in pollen loads and nectar brought back to the hive by foragers. From the 780 pollen samples, a subset of 450 samples was selected in order to get at least one sample per plot and per month (Appendix B). After homogenization of the 450 pollen samples, 4-g subsamples were withdrawn, diluted in water, and mounted onto microscope slides for pollen species identification. Slides were stained with Fuschin and examined at $400 \times$ magnification with an Olympus BH-2 microscope (Olympus, Paris, France) fitted with a numeric camera (Pégase Pro V4, Software 2I system, Paris, France). Pollen was identified to species whenever possible (Appendix C), to genus (e.g., Prunus for the 
closely related $P$. avium, $P$. spinosa, and $P$. cerasus), or to family (e.g., Asteraceae). A counting "transect" method (Tamic et al. 2011) was performed on each slide until at least 300 pollen grains were counted and identified according to a local palynological reference collection (e.g., Ricciardelli D'Albore 1998, Bucher et al. 2004, Odoux et al. 2005). This method may somehow underestimate rare pollen species (Louveaux et al. 1978) or overestimate those with large diameter (Dasilveira 1991), but provides satisfactory snapshots of the overall bee diet. We finally computed the contribution of each pollen species $(i)$ to total mass (Mass, g) of collected pollen in a sample $(j)$ by weighting the pollen species occurrence frequency $\left(n_{i}\right.$, number of pollen grains of species $i$ averaged between the two subsamples) by the pollen grain species-specific diameters $\left(d_{i}\right)$

$$
\operatorname{Mass}_{i, j}=\frac{\left(n_{i} \times d_{i}\right)_{j}}{\sum_{i}\left(n_{i} \times d_{i}\right)_{j}} \times \operatorname{Mass}_{j}
$$

To improve accuracy, the identification process was duplicated and the resulting Mass values were averaged between the duplicates. In order to avoid overweighting rare pollen species whose occurrence at trace level in samples may be unrelated to foraging events, all analyses were recomputed after excluding species occurrence frequency values accounting for $<1 \%$ of pollen species in each sample.

Determining the botanical origins of nectar is less straightforward and notoriously more difficult than for pollen (Louveaux et al. 1978, Anklam 1998, Von Der Ohe et al. 2004). Usual methods rely on melissopalinology, i.e., the identification of incidental pollen grains ingested by nectar foragers and subsequently regurgitated and stored in honey reserves (Louveaux et al. 1978, Sabo et al. 2011). This approach may help identify the main plant species foraged for nectar, but is not adequate for quantitative assessment of the less common plant species. Incidental pollen grains unrelated with nectar foraging may also artificially raise the plant species richness estimates of nectar botanical origin. For those reasons, although we applied the same analytic approach used for the pollen diet (see Eq. 1), we only report broad categories of plant species contributions to total honey sample mass: dominant species $(>45 \%$ of total mass), common species (15-45\%), and rare species $(<15 \%$; see also Louveaux et al. 1978). Pollen grains were identified from $500 \mathrm{~g}$ of honey samples from the honey stored in hive super-chambers and obtained by homogenizing equal amounts of honey from the five hives within each monitored apiary. The botanical origins of nectar were assessed only for the two periods of honey extraction by beekeepers (May and August, $n=$ 67 nectar harvests; Appendix B).

\section{Nutritional characteristics of dominant pollen species}

We quantified the nutritional value of pollen (protein and mineral contents) for the plant species that accounted for more than $1 \%$ of the diet mass on an annual basis (15 plant species; Appendix C). To do so, we first isolated monospecific pollen subsamples of those target species by manually extracting specific pollen loads from pollen samples where those species were classified as dominant ( $>50 \%$ of pollen mass; Appendix A). The purity of monospecific subsamples was controlled by microscope observations and validated if the target species accounted for $>95 \%$ of pollen grains. For each of the 56 monospecific subsamples eventually selected (three to seven per species), we extracted and freeze dried $5 \mathrm{~g}$ of pollen loads. The mineral content of the dry matter was determined using gravimetry (ISO 5984 norm) by measuring the percent difference in mass between the initial mass of the pollen sample and its remaining residual mass after $6 \mathrm{~h}$ of calcination at $550^{\circ} \mathrm{C}$. The crude protein content was assessed from the determination of nitrogen $(\mathrm{N})$ content using the Kjeldahl method (percent $\mathrm{N} \times 6.25$; ISO 5983-2 norm) and a Vapodest 45 Gerhardt automat (Gerhardt ${ }^{\circledR}$, Königswinter, Germany). The gross energy was obtained using an IKA C 7000 calorimeter system (IKA, Staufen, Germany).

\section{Statistical analyses}

Seasonal pattern of pollen and nectar collected mass.The time series data of pollen dry mass $(n=780$ pollen samples) and brood-chamber nectar mass ( $n=1460$ nectar samples) returned by the bimonthly colony routine survey were log-transformed (for pollen) and modeled as a spline function of time using generalized additive mixed models (GAMMs) with a Gaussian error structure. GAMMs are modeling techniques used to fit temporal splines to data while accounting for repeated measurements within a nested design. Herein, the identities of year, apiary, and colony were specified as a suit of nested random grouping variables. Time was rescaled on Julian dates from the first of January and corrected for inter-annual deviations of climatic conditions (Appendix D). Model residuals were extracted and inspected against fitted values (residuals vs. fitted plot and normal Q-Q plot) to ensure residual normality and homoscedasticity assumptions were fulfilled. Finally, peaks and troughs in the seasonal pattern were a posteriori determined using the breakpoints function of the R package strucchange (Zeileis et al. 2002).

Contribution of flowering crops vs. other floral resources to honey bee diet.-We assigned the floral resource taxonomic identity in honey bee diet (pollen and nectar) to four broad resource types based on life forms and management, namely: cropped species, herbaceous plant species, woody plant species, and finally horticultural plant species (Appendix C). We used chi-squared tests to compare, among seasonal peaks and troughs periods, the relative contribution of these four resource types.

Floral resource diversity in pollen ( $n=450$ pollen samples) and nectar ( $n=67$ nectar samples) was estimated using the total observed species richness 
(number of distinct pollen species), the expected species richness returned by the Chao 1 estimator, as well as the Shannon index of species equitability (Gotelli and Colwell 2001). Equitability ranges from 0 (only one species sampled) to 1 (all species being equally sampled). The variations of species richness and equitability of foraged plants among resource collection peak and trough periods were tested using generalized linear mixed models (GLMMs) with a Gaussian error structure, a suit of nested factors for identity of sampling levels (see above), as well as a posteriori multiple pairwise comparisons.

Nutritional characteristics of dominant pollen species.-The relationship between pollen nutritional value (protein and mineral contents) and mean contribution to collected pollen mass throughout samples was assessed using Spearman rank tests for the 15 most frequently collected pollen species. The correlation analysis was performed separately for each seasonal peak and trough period in order to depict possible seasonal variations in honey bee preference patterns.

Influence of local landscape context on diet composition.-In order to compare pollen diet composition among apiaries, we computed the Jaccard dissimilarity index, ranging from 0 (complete similarity between two samples, i.e., between two plots) to 1 (complete dissimilarity). The pairwise dietary dissimilarity values between apiaries were modeled as a function of pairwise Euclidian distance and pairwise dissimilarity of landscape composition between apiaries. Under the assumption that the local landscape context influences honey bee diet, we expected neighboring apiaries to display more similar diets than apiaries located further away from each other, unless located in different landscape types. Landscape composition dissimilarity was computed using the Jaccard index, 10 land cover categories (forests and hedgerows, roadsides, grasslands, rapeseed, sunflower, leguminous crops, polliniferous cereal crops, other cereals, other crops, and built-up areas) obtained from the local GIS resources, and by focusing on a 1500 $\mathrm{m}$ radius around each apiary (see Steffan-Dewenter and Kuhn [2003] for the choice of radius). The most parsimonious association of explanatory variables for pollen diet dissimilarity (pairwise distance, landscape dissimilarity, month, and their two-way interactions) was determined using GAMMs, with specifications analogous to the above-described seasonal pattern analysis and an AIC-based model simplification procedure.

All statistical analyses were performed using the $\mathrm{R}$ environment for statistical computing version 2.11.1 ( $\mathrm{R}$ Development Core Team 2009).

\section{RESUlts}

\section{Seasonal pattern of pollen and nectar collected mass}

After controlling for inter-annual deviations of climatic conditions, we found a strong seasonal variation in the pollen and nectar collected mass. Pollen collection follows a bimodal pattern with two peaks (10 May to 6 June, and 14 July to 16 August; Fig. 1a) preceded and followed by periods of lower collecting levels. Seasonal variation in pollen mass was highly significant (GAMM, $F_{6,773}=7.333, P<0.001$ ). Unexpectedly, the first peak in pollen mass occurred one month after the peak in rapeseed blooming. Conversely, the second peak in July coincided with the blooming of sunflower and maize.

Likewise, the mass of nectar in the brood chamber of hives (i.e., excluding honey collected by beekeepers in super-chambers $)$ followed a bimodal pattern $\left(F_{4,1455}=\right.$ 375.9, $P<0.001)$ with a poorly marked peak in spring (from 12 April to 10 May) and a sharper one in summer (from 19 July to 21 August). These two periods coincided with the blooming periods of the two dominant oilseed crops, i.e., successively rapeseed and sunflower (Fig. 1b). Therefore, pollen and nectar collections peaked simultaneously only during the sunflower blooming period.

\section{Contribution of flowering crops vs. other floral resources to honey bee diet}

In our intensive cereal system, honey bees collected a highly diverse range of floral species, with a total of 228 identified species (Appendix C) in pollen samples $(n=$ 450 pollen samples) from April to September. Total expected pollen species richness is estimated to $271 \pm$ 17.6 species (mean \pm SD). The sampling completeness had therefore reached an acceptable level of $84 \%$. Despite the acknowledged methodological difficulties for assessing the botanical origins of nectar, we found a tentative estimate of 82 floral species $(n=67$ nectar samples; total expected richness $=101 \pm 11.8$, sampling completeness $=81 \%$ ).

Pollen diet species richness and diversity were highest in May (Fig. 2a and b). In total, 90.2\% of species foraged for nectar were also foraged for pollen. On a daily basis, the number of collected species as well as their equitability were lower for nectar than for pollen (GLMM, $F_{1,464}=42.83, P<0.001$, and $F_{1,464}=207.75$, $P<0.001$, respectively), indicating that despite different sampling efforts between pollen and nectar diet, honey bees did forage on fewer species for nectar than for pollen. Restricting the data set to species for which occurrence exceeded $1 \%$ did not alter the difference for species richness $\left(F_{1,464}=221.30, P<0.001\right)$ while there was no longer a difference for equitability $\left(F_{1,423}=0.03\right.$, $P=0.862)$.

Overall, cropped plants were the second most dominant source of pollen and accounted for $30.2 \%$ of total pollen mass on an annual basis (Fig. 3a). Compared to the other three resource types that were combined along the season, bees foraged on crops less than on other resource types $\left(\chi^{2}=14.80\right.$, df $=1, P<$ 0.001 ). Early in the season, cropped species (represented by rapeseed) were less used for pollen (11\%) than other floral resources. In contrast, honey bees heavily relied on 

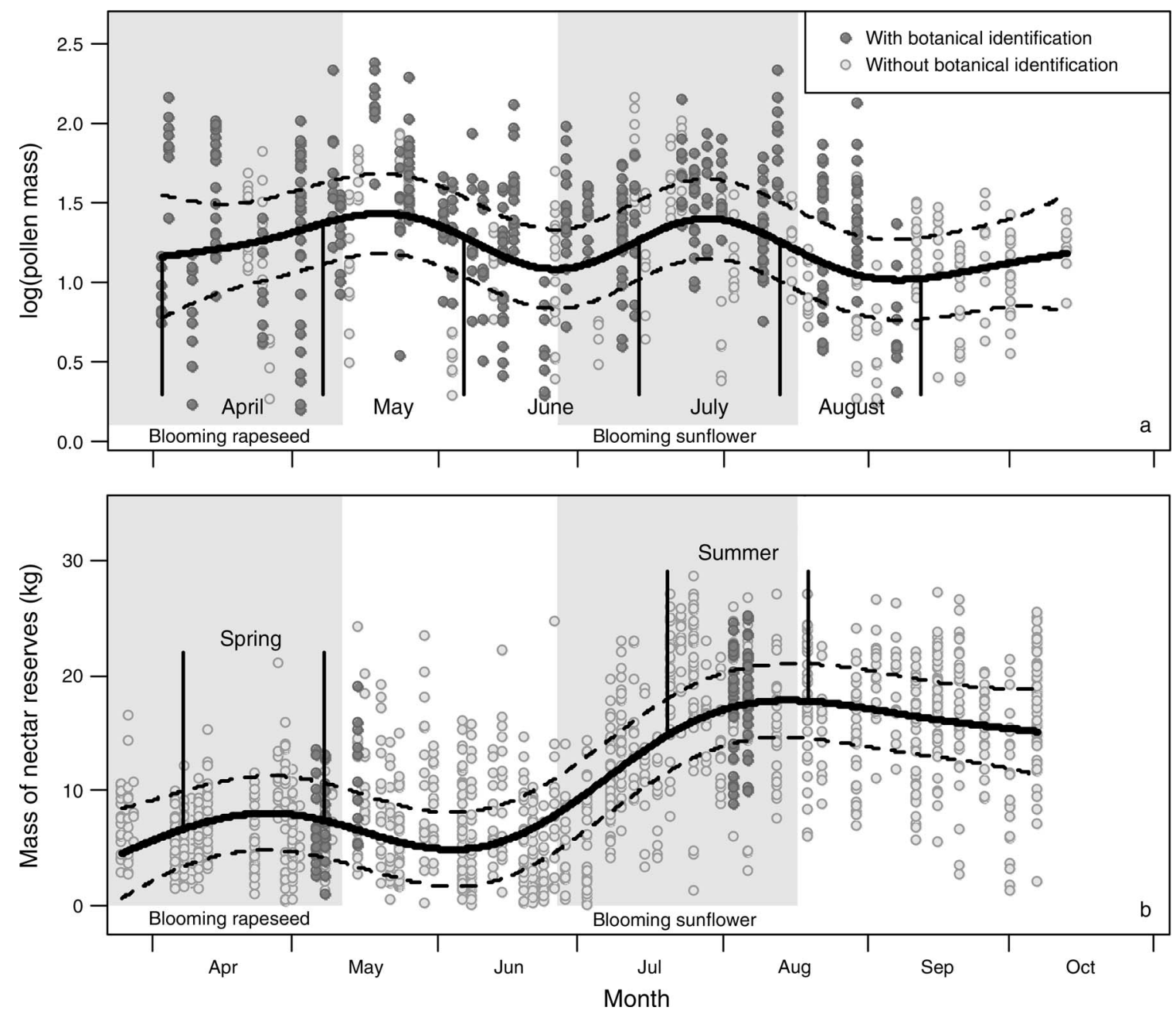

FIG. 1. Seasonal patterns of (a) pollen mass ( $\mathrm{g}, n=780$ pollen samples) and (b) nectar reserve mass in brood chambers ( $\mathrm{kg}$, $n=$ 1640 nectar samples). The thick line shows GAMM predictions (see Methods) and dashed lines show the confidence interval envelope $(95 \% \mathrm{CI})$. The vertical lines delineate the temporal extent of spring and summer seasons. Light gray shading delineates mass-flowering periods of rapeseed and sunflower crops. Each point represents an observed value; dark gray points represent the subset of pollen samples selected for botanical identification $(n=450$ pollen samples). Notice the log scale attenuates the seasonal peaks in pollen mass.

woody and herbaceous plant species (including weeds) from semi-natural habitats to meet their pollen requirements $\left(\chi^{2}=8.43, \mathrm{df}=1, P<0.01\right)$, totaling more than $60 \%$ of annual pollen diet. Woody plant species, including Crataegus sp., Prunus sp., and Acer sp. accounted for the bulk of the pollen diet in April (Fig. 3b). The poppy (Papaver rhoeas) was the most collected herbaceous plant species and was the second most dominant species in the annual pollen diet after maize and before sunflower. Poppy was mostly collected in June, i.e., during the depletion period of pollen mass between crop blooms (Fig. 3b). Horticultural plant species, typically found in gardens, were only marginally used (Fig. 3a). Contrary to pollen, nectar diet mainly proceeded from the dominant cropped species $\left(\chi^{2}=\right.$ $68.88, \mathrm{df}=1, P<0.001$, Fig. 3c). During spring, nectar mass was largely dominated by rapeseed, while sunflower dominated nectar mass during summer (Fig. 3d).

\section{Nutritional value of dominant pollen species}

Using only the 15 most frequently collected species, we found that the relationship between the mean collected pollen mass and parameters depicting pollen quality (protein and mineral content) decreased with season $\left(F_{1,14}=71.1, P<0.01\right.$ and $F_{1,14}=30.0, P<0.05$, respectively). Early in the season (April), honey bees collected nutrient-rich pollen, with protein- and mineralrich pollen contributing most to collections (Fig. 4). One noticeable exception was rapeseed pollen, being little collected although rich in proteins, minerals, and energy (Appendix E). In contrast, honey bees did not collect pollen according to nutritional value at the end of the season as there was no significant relationship between 

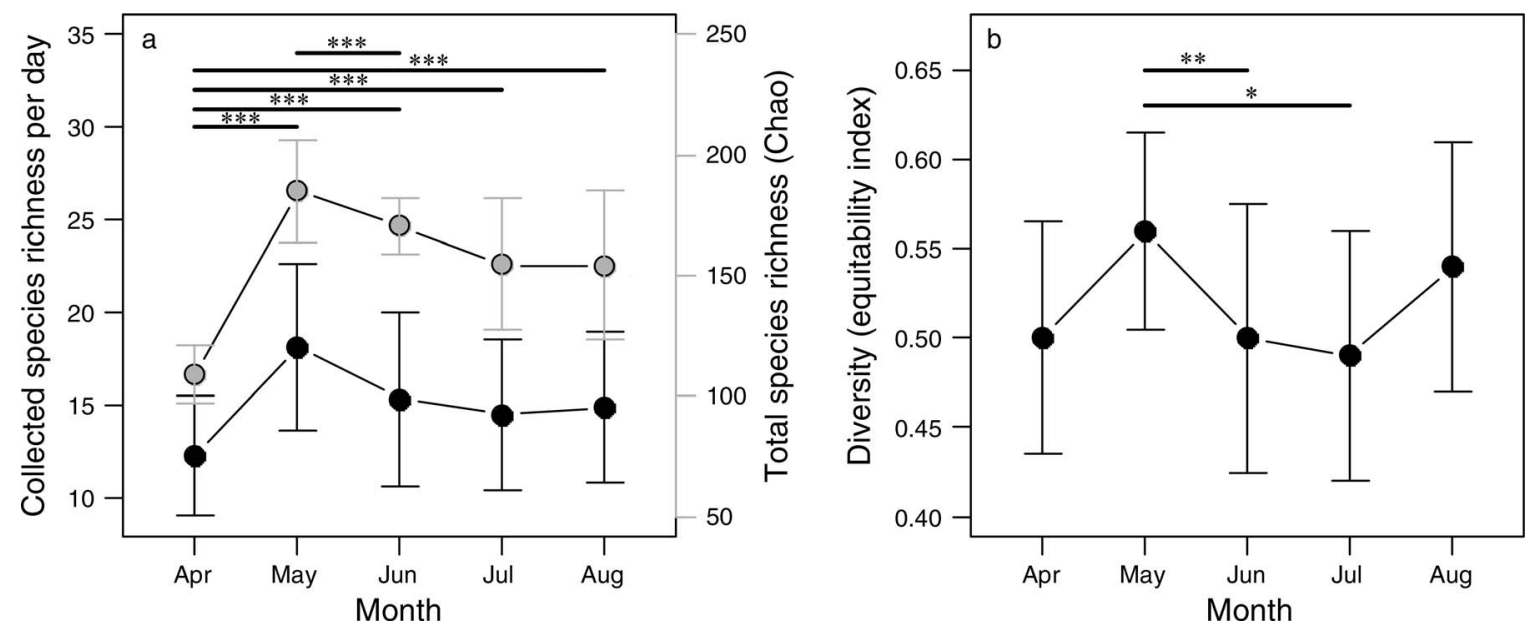

FIG. 2. Plant species richness and diversity of the pollen diet ( $n=450$ pollen samples). (a) Pollen species richness for each month (black circles) with associated $P$ values indicating significant differences in species richness between months, and the total species richness estimated for each month using the Chao 1 estimator (gray circles). (b) Floral species diversity for each month (Shannon equitability index) with associated $P$ values indicating significant differences in diversity between months. Values are means \pm SE.

$* P<0.05 ; * * P<0.01 ; * * * P<0.001$.
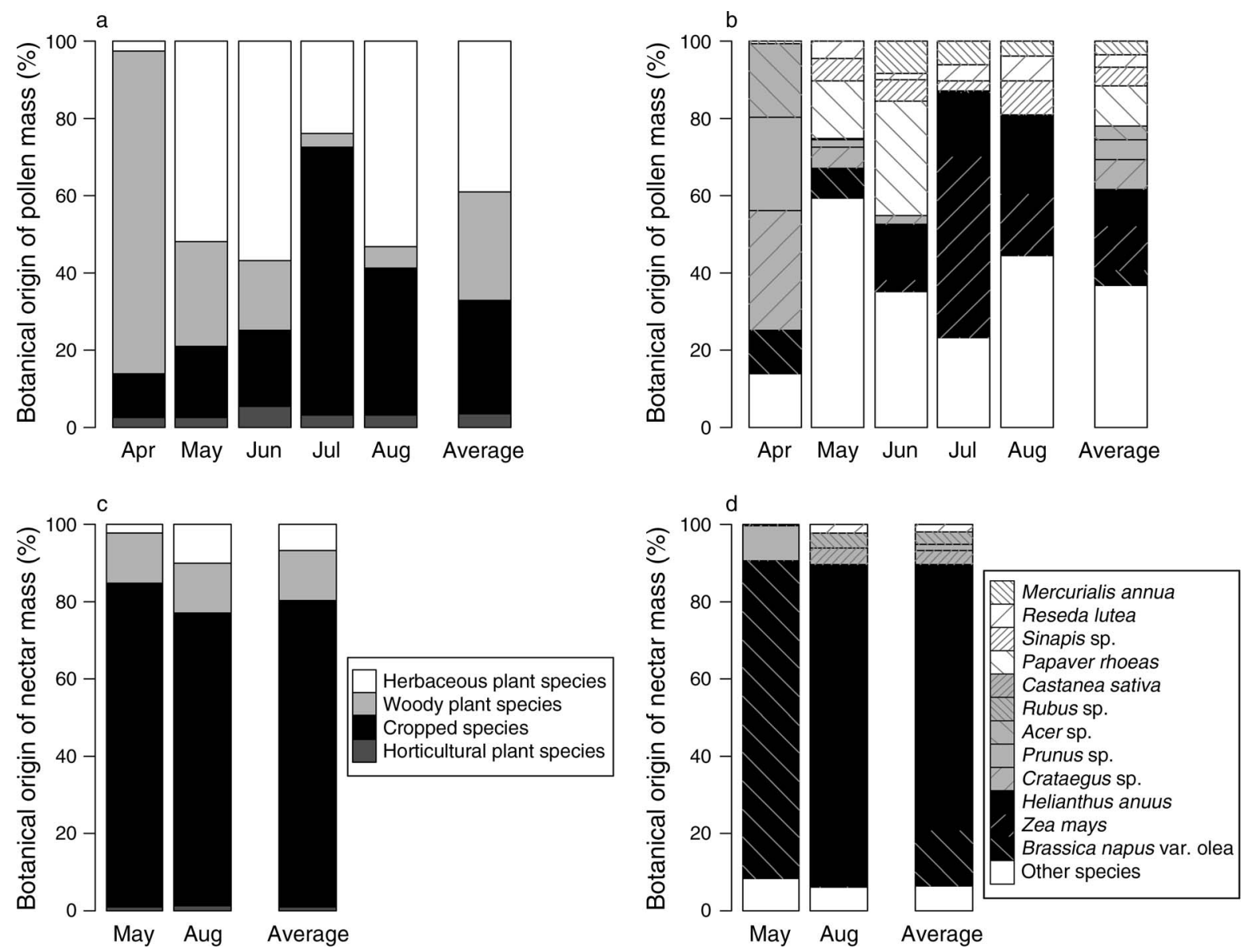

FIG. 3. Botanical origins and taxonomic identities of $(a, b)$ bee-collected pollen and $(c, d)$ nectar, expressed as a percentage of total pollen mass $(n=450$ pollen samples) and nectar mass $(n=67$ nectar samples), respectively. The botanical origins of nectar were assessed only for the two periods of honey extraction by beekeepers (May and August). The botanical origins of pollen were assessed only around the blooming period of rapeseed and sunflower (from April to August) in order to assess the respective contribution of crops vs. other floral resources to honey bee diet. 


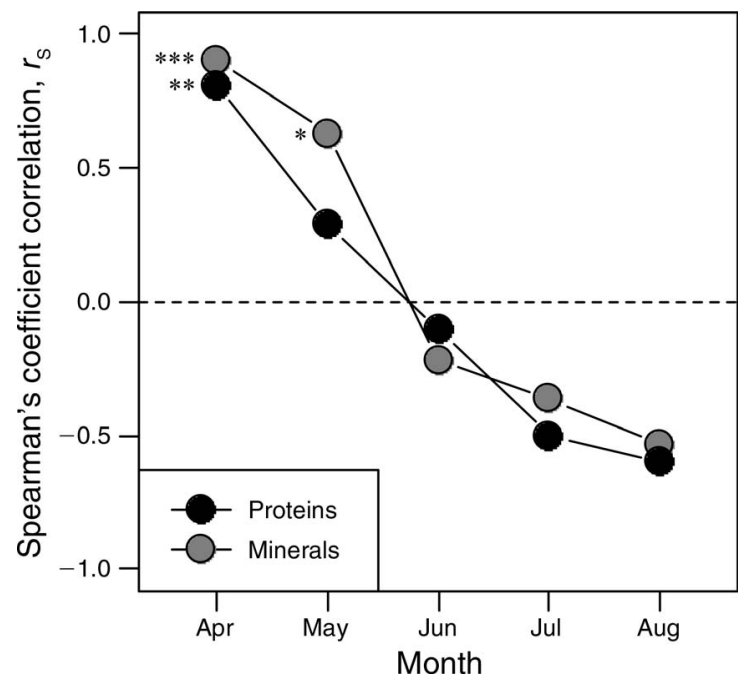

FIG. 4. Spearman's rank correlation coefficients $\left(r_{\mathrm{S}}\right)$ of regression models evaluating relationships between pollen protein content (black circles), pollen mineral content (gray circles), and total pollen mass (log-transformed) according to month ( $n=56$ monospecific pollen subsamples).

${ }^{*} P<0.05 ; * * P<0.01 ; * * * P<0.001$.

pollen mass and pollen quality. In particular, maize and sunflower pollen where heavily collected despite having low protein and mineral contents.

\section{Influence of local landscape context on diet composition}

The dissimilarity value of pollen diet composition between apiaries (within a given seasonal period of a given year) was on average $0.47 \pm 0.11$. This intermediate value indicates that half of the pollen species were different from one apiary to another, therefore indicat- ing specific local dietary compositions. This was further supported by a low average species richness in pollen mass collected per apiary and per year (62.8 species) relative to the total pool of species from which pollen was collected in the study area (228 species). In other words, each apiary exploited on average only $29.3 \%$ of the total collected floral community at the study area scale (range: $20.6-42.1 \%, n=50$ ).

The GAMM modeling framework indicated that pollen diet dissimilarity among apiaries was not stationary throughout the season. The highly significant temporal spline $\left(F_{3,1057}=18.11, P<0.001\right)$ delineates a marked dissimilarity peak in June, i.e., during the depletion period of pollen mass between the two crop blooms (Fig. 5a). Beyond this general seasonal pattern, pollen diet dissimilarity was positively and significantly associated with geographic distance among apiaries $\left(F_{1,1059}=7.36, P<0.001\right)$ and landscape composition dissimilarity $\left(F_{1,1059}=2.79, P=0.010\right)$; this conforms to the hypothesis that honey bee diet is locally constrained by the landscape context (Fig. 5b). The AIC-based model simplification procedure indicated that neither expressing distance and landscape dissimilarity as spline (rather than linear) function of pollen diet, nor associating them in interaction with the temporal spline would improve the model fit to the data $(\triangle \mathrm{AIC}$ was greater than 4 in all cases).

\section{DiscusSION}

\section{Seasonal patterns of pollen collections do not strictly match oilseed crop blooms}

The coincidence between crop blooms and honey bee diet actually fit well for nectar but not for pollen, where the first collecting peak occurred one month after rapeseed blooming. Therefore, while levels of nectar
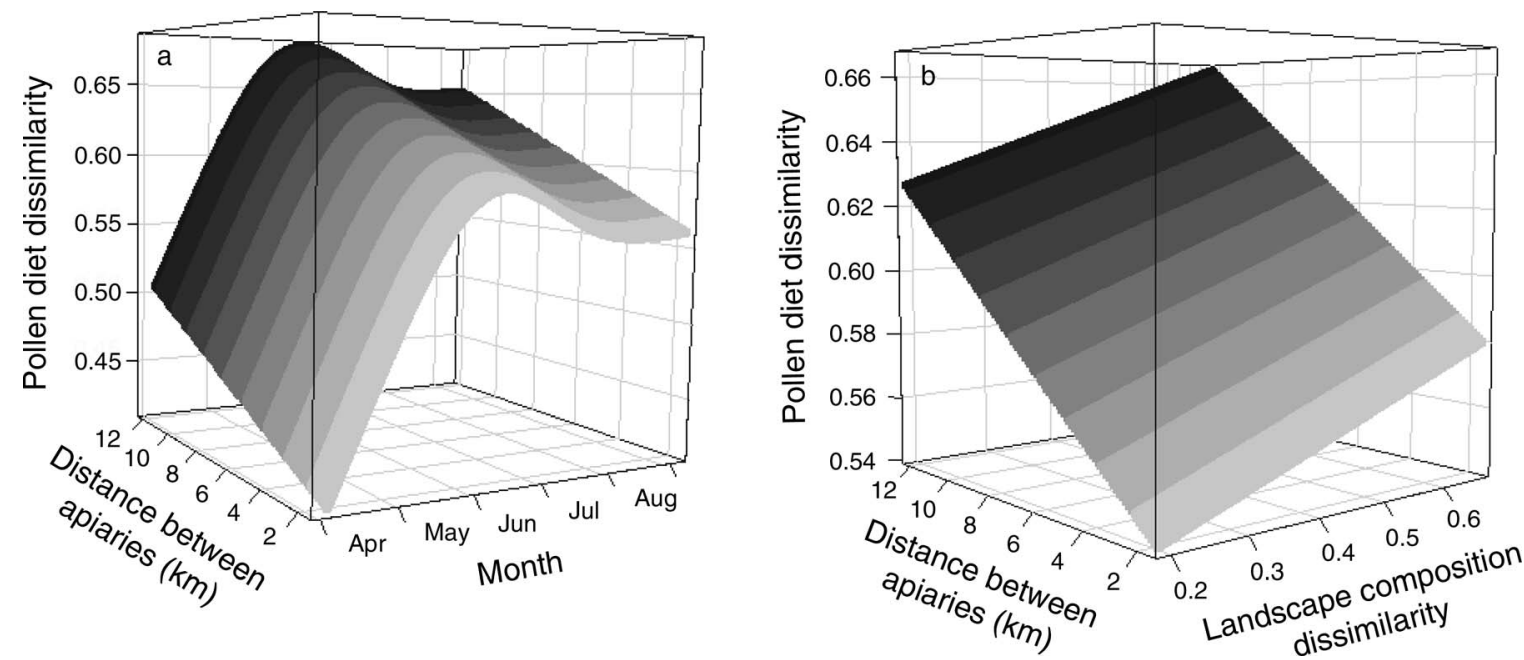

FIG. 5. Pollen diet dissimilarity between apiaries (a) as a function of month (corrected for phenological lag) and pairwise distance between apiaries $(\mathrm{km})$, and (b) as a function of landscape composition dissimilarity and pairwise distance between apiaries (from a GAMM model, $n=1061$ ). Jaccard dissimilarity index values range from 0 (complete similarity) to 1 (complete dissimilarity). The gray gradient indicates graphical depth. 


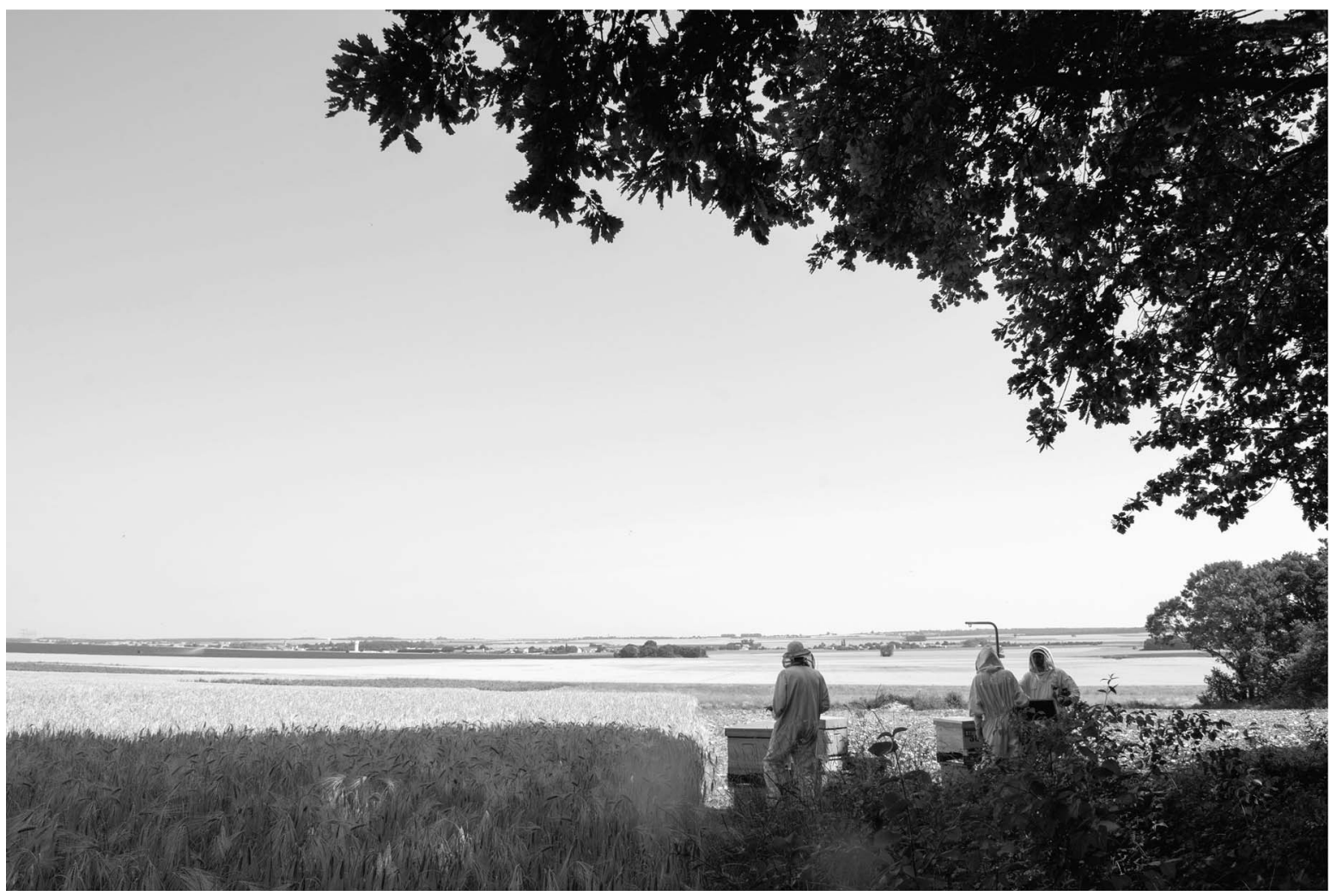

Plate 1. The Long-Term Ecological Research “Zone Atelier Plaine and Val de Sèvre” in central western France (46 $23^{\circ}$ N, $0^{\circ} 41^{\prime} \mathrm{W}$ ) has hosted a study about honey bee ecology since 2008 through the ECOBEE platform. In this intensive cereal system, 250 bee colonies were monitored and managed from March to October according to local beekeeping professional practices. Photo credit: Christophe Maitre/INRA.

income appeared to be driven by the availability of the two dominant oilseed crops in intensive farmland habitats (Varis 2000), pollen diet seemed to be driven by crops only during summer. At the first pollen peak, honey bees massively foraged on floral species from semi-natural habitats (e.g., Acer sp., Prunus sp., Crataegus sp.) rather than rapeseed for pollen needs. Rapeseed crop accounts for approximately $10 \%$ of the crop surface, similar to that of sunflower and maize; this suggests that rapeseed was counter selected compared to sunflower for the pollen diet. Rapeseed has protein, mineral, and energy values that are comparable to those of other plant species from semi-natural habitats that are used by honey bees during the same flowering period (Appendix E). However, other pollen quality parameters may explain the apparent rapeseed avoidance by bees. For example, the smaller pollen diameter of rapeseed (Appendix E) could slow down the collection task. Indeed, Odoux et al. (2014) have shown that bee colonies are mainly at an immature stage during this period of mass flowering (Appendix F), and nursing bees are the ones that mostly consume pollen to develop the glands that produce food for larvae (Haydak 1970). Therefore, we suggest that the relative avoidance of rapeseed for pollen by honey bees may result from a preference for high nutritional value (protein, mineral and energy) in order to feed the large number of bees at immature stages. Accordingly, the most abundant pollen species collected by honey bees early in the season (April-May) are significantly more nutrient rich than the rarest pollen species. Conversely, later in the season (June and later on), no relationship was found between collected pollen mass and nutritional value. However, in the absence of accurate data on floral resource availability (not collected in this study), one cannot firmly conclude a potential honey bee selectivity with regard to pollen quality (see also Pernal and Currie 2002).

\section{Major contribution of weeds and trees to pollen collections}

The observed bimodal pattern of honey bee diet, i.e., including a two-month food supply depletion period, may be perceived as an environmental stress for both honey bees and beekeeping activity (see also Couvillon et al. 2014). This food supply depletion period could affect colony health and sustainability because it occurs when colonies are at their maximal population size (larvae and adult; Appendix F). Such variations in food quantity have indeed led beekeepers to provide supplements of food substitutes to prevent nutritional defi- 
ciency and colony failure at this period (F. Requier, J. F. Odoux, and V. Bretagnolle, personal observations).

We also found that honey bees rely on a very wide diversity of plants for their pollen needs throughout the season, even during the crop flowering blooms (see also Odoux et al. 2012). Some authors suggest honey bees need polyfloral pollen rather than monofloral (Schmidt 1984; but see Di Pasquale et al. 2013); furthermore, the pollen resource diversity enhances resistance to fungal diseases, tolerance to pesticides, and immunity in honey bees to parasites, diseases, and pathogens (e.g., Alaux et al. 2010, Di Pasquale et al. 2013). The entire colony is defined as the summed populations of adults and larvae. Our results thus suggest that honey bees use a wide variety of resources for their pollen diets in order to ensure the health of the entire colony. This may explain why bees foraged on more plant species than expected during rapeseed blooming, especially since larvae wee numerous during this period. Interestingly, we found that pollen diet composition was most variable between apiaries during the food supply depletion period, and was also best explained by landscape context variables, which were, to a large extent, specific to each apiary.

\section{Implications for bee-pollinator conservation and sustainable honey production in agricultural landscapes}

Enhancing the quality of honey bee foraging habitat in farmlands can take a number of forms, although the most often used management techniques consist of sowing and maintaining diverse native or non-native flower-rich mixes in set-aside areas such as fallows, field margins, and conservation buffer strips (Haaland et al. 2011, Wratten et al. 2012). However, Agri-Environmental Schemes (AES) have been developed so far without (or with very little) knowledge of honey bee diet in intensive cereal systems. To overcome the need to feed the colonies artificially during this period of food supply depletion, it is necessary to increase either the diversity of crops or the abundance and diversity of floral resources in association with crops (weeds), grasslands, or semi-natural elements (hedgerows, field margins). The first option includes the reintroduction of entomophilous crops in cropping systems such as Fabaceae, which are extensively visited by bees (Rollin et al. 2013).

Alternatively, since honey bees use a broad range of available floral resources in the landscape to fulfill their pollen needs, increasing semi-natural habitat land cover and their associated flora may strongly contribute to the honey bee diet. The conservation of semi-natural habitats and plant diversity are also consistent with the safeguarding of native bees (wild bees and bumble bees) and can enhance overall biodiversity and ecosystem services (Wratten et al. 2012, Nicholls and Altieri 2013).

A third alternative is weed conservation, as weeds are an essential resource for pollen diet because of their continuous flowering phenology (especially during the late spring period) and their high species richness, which contributes directly to the pollen diversity need. Weeds represent a substantial part of the honey bee annual diet, in particular poppy. Weed conservation could be achieved with less intensive agricultural practices, including a reduction in the use of herbicides and fertilizers that are known to drastically restrict weed species richness and abundance (Marshall et al. 2003); this conservation approach has been planned in some European countries (Barzman and Dachbrodt-Saaydeh 2011). These promising solutions are consistent with the conservation of other beneficial species involved in ecosystem services of agricultural landscapes such as pest control by natural predator insects (Bianchi et al. 2006), and the conservation of rare plant species and associated pollinators (Gibson et al. 2006).

\section{ACKNOWLEDGMENTS}

This work was supported by grants from the French Ministry of Agriculture (CASDAR, POLINOV program no. 9535), the Poitou-Charentes Region, and the European Community Program (797/2004) for French beekeeping (convention France Agrimer 14-03R). Special thanks to Pierrick Aupinel, Clovis Toullet, and Mélanie Chabirand at INRA Le Magneraud, and Claire Le Mogne (Beekeeper at ADA Poitou-Charentes) for help with field work. We thank the France Miel for the melliso-palynological assistance and Dalila Feuillet for technical support concerning physicochemical analysis. We also thank Barbara Butcher for critical reading of English used in the text, as well as two anonymous referees for improving the text.

\section{Literature Cited}

Alaux, C., F. Ducloz, D. Crauzer, and Y. Le Conte. 2010. Diet effects on honeybee immunocompetence. Biology Letters 6:562-565.

Anklam, E. 1998. A review of the analytical methods to determine the geographical and botanical origin of honey. Food Chemistry 63:549-562.

Barzman, M., and S. Dachbrodt-Saaydeh. 2011. Comparative analysis of pesticide action plans in five European countries. Pest Management Science 67:1481-1485.

Bianchi, F., C. J. H. Booij, and T. Tscharntke. 2006. Sustainable pest regulation in agricultural landscapes: a review on landscape composition, biodiversity and natural pest control. Proceedings of the Royal Society B 273:17151727.

Bucher, E., V. Kofler, G. Vorwohl, and E. Zieger. 2004. Lo spettro pollinico dei mieli dell'Alto Adige. Laboratorio Biologico, Agenzia Provinciale per l'Ambiente, Laives, Italy.

Couvillon, M. J., R. Schurch, and F. L. W. Ratnieks. 2014. Waggle dance distances as integrative indicators of seasonal foraging challenges. PLoS ONE 9:7.

Dasilveira, F. A. 1991. Influence of pollen grain volume on the estimation of the relative importance of its source to bees. Apidologie 22:495-502.

Di Pasquale, G., M. Salignon, Y. Le Conte, L. P. Belzunces, A. Decourtye, A. Kretzschmar, S. Suchail, J. L. Brunet, and C. Alaux. 2013. Influence of pollen nutrition on honey bee health: do pollen quality and diversity matter? PLoS ONE $8: 13$.

Gibson, R. H., I. L. Nelson, G. W. Hopkins, B. J. Hamlett, and J. Memmott. 2006. Pollinator webs, plant communities and the conservation of rare plants: arable weeds as a case study. Journal of Applied Ecology 43:246-257.

Godfray, H. C. J., J. R. Beddington, I. R. Crute, L. Haddad, D. Lawrence, J. F. Muir, J. Pretty, S. Robinson, S. M. Thomas, 
and C. Toulmin. 2010. Food security: the challenge of feeding 9 billion people. Science 327:812-818.

Gotelli, N. J., and R. K. Colwell. 2001. Quantifying biodiversity: procedures and pitfalls in the measurement and comparison of species richness. Ecology Letters 4:379-391.

Haaland, C., R. E. Naisbit, and L. F. Bersier. 2011. Sown wildflower strips for insect conservation: a review. Insect Conservation and Diversity 4:60-80.

Haydak, M. H. 1970. Honey nee nutrition. Annual Review of Entomology 15:143-156.

Keller, I., P. Fluri, and A. Imdorf. 2005. Pollen nutrition and colony development in honey bees-part II. Bee World 86:27-34.

Klein, A. M., B. E. Vaissiere, J. H. Cane, I. Steffan-Dewenter, S. A. Cunningham, C. Kremen, and T. Tscharntke. 2007. Importance of pollinators in changing landscapes for world crops. Proceedings of the Royal Society B 274:303-313.

Lavie, P., and J. Fresnaye. 1963. Étude expérimentale de la trappe à pollen en position supérieure. Annales de l'abeille 6:277-301.

Louveaux, J., A. Maurizio, and G. Vorwohl. 1978. Methods of melissopalynology. Bee World 59:139-157.

Marshall, E. J. P., V. K. Brown, N. D. Boatman, P. J. W. Lutman, G. R. Squire, and L. K. Ward. 2003. The role of weeds in supporting biological diversity within crop fields. Weed Research 43:77-89.

Naug, D. 2009. Nutritional stress due to habitat loss may explain recent honeybee colony collapses. Biological Conservation 142:2369-2372.

Nicholls, C. I., and M. A. Altieri. 2013. Plant biodiversity enhances bees and other insect pollinators in agroecosystems. A review. Agronomy for Sustainable Development 33:257274.

Odoux, J. F., P. Aupinel, S. Gateff, F. Requier, M. Henry, and V. Bretagnolle. 2014. ECOBEE: a tool for long-term bee colony monitoring at landscape scale in West European intensive agrosystems. Journal of Apicultural Research 53:57-66.

Odoux, J. F., D. Feuillet, P. Aupinel, Y. Loublier, J. N. Tasei, and C. Mateescu. 2012. Territorial biodiversity and consequences on physico-chemical characteristics of pollen collected by honey bee colonies. Apidologie 43:561-575.

Odoux, J. F., H. Lamy, A. Girardeau, F. Minier, and P. Aupinel. 2005. Une ressource documentaire botanique sur internet pour les apiculteurs. Bulletin Technique Apicole 32:165-170.

Pernal, S. F., and R. W. Currie. 2002. Discrimination and preferences for pollen-based cues by foraging honeybees, Apis mellifera L. Animal Behaviour 63:369-390.

Potts, S. G., J. C. Biesmeijer, C. Kremen, P. Neumann, O. Schweiger, and W. E. Kunin. 2010. Global pollinator declines: trends, impacts and drivers. Trends in Ecology and Evolution 25:345-53.

R Development Core Team. 2009. R: a language and environment for statistical computing. R Foundation for
Statistical Computing. Vienna, Austria. http://www. R-project.org.

Rader, R., B. G. Howlett, S. A. Cunningham, D. A. Westcott, L. E. Newstrom-Lloyd, M. K. Walker, D. A. J. Teulon, and W. Edwards. 2009. Alternative pollinator taxa are equally efficient but not as effective as the honeybee in a massflowering crop. Journal of Applied Ecology 46:1080-1087.

Ricciardelli D'Albore, G. 1998. Mediterranean melissopalynology. Università degli studi di Perugia, Facoltà di agraria, Istituto di entomologia agrarian, Perugia, Italy.

Rollin, O., V. Bretagnolle, A. Decourtye, J. Aptel, N. Michel, B. E. Vaissière, and M. Henry. 2013. Differences of floral resource use between honey bees and wild bees in an intensive farming system. Agriculture, Ecosystems and Environment 179:78-86.

Sabo, M., M. Potocnjak, I. Banjari, and D. Petrovic. 2011. Pollen analysis of honeys from Varazdin County, Croatia. Turkish Journal of Botany 35:581-587.

Schmidt, J. O. 1984. Feeding preferences of Apis mellifera L. (Hymenoptera: Apidae): individual versus mixed pollen species. Journal of the Kansas Entomological Society 57:323-327.

Steffan-Dewenter, I., and A. Kuhn. 2003. Honeybee foraging in differentially structured landscapes. Proceedings of the Royal Society B 270:569-575.

Tamic, T., P. Aupinel, J. F. Odoux, Y. Loublier, and M. Chabirand. 2011. Optimisation d'une méthode de dénombrement de grains de pollen adaptée a l'étude de l'alimentation de l'abeille domestique. Polen 21:51-55.

Tilman, D., J. Fargione, B. Wolff, C. D'Antonio, A. Dobson, R. Howarth, D. Schindler, W. H. Schlesinger, D. Simberloff, and D. Swackhamer. 2001. Forecasting agriculturally driven global environmental change. Science 292:281-284.

Vanbergen, A. J., and the Insect Pollinators Initiative. 2013. Threats to an ecosystem service: pressures on pollinators. Frontiers in Ecology and the Environment 11:251-259.

Varis, A. L. 2000. Influence of changes in crop cultivation areas on pollen contents of honey. Agricultural and Food Science in Finland 9:253-257.

Von Der Ohe, W., L. Persano Oddo, M. L. Piana, M. Morlot, and P. Martin. 2004. Harmonized methods of melissopalynology. Apidologie 35:S18-S25.

Winfree, R., R. Aguilar, D. P. Vazquez, G. LeBuhn, and M. A. Aizen. 2009. A meta-analysis of bees' responses to anthropogenic disturbance. Ecology 90:2068-2076.

Wratten, S. D., M. Gillespie, A. Decourtye, E. Mader, and N. Desneux. 2012. Pollinator habitat enhancement: benefits to other ecosystem services. Agriculture, Ecosystems and Environment 159:112-122.

Zeileis, A., F. Leisch, K. Hornik, and C. Kleiber. 2002. strucchange: an R package for testing for structural change in linear regression models. Journal of Statistical Software 7:138.

\section{Supplemental Material}

\section{Ecological Archives}

Appendices A-F are available online: http://dx.doi.org/10.1890/14-1011.1.sm 